\title{
Microstructural differences of fibrin and self- assembling peptide hydrogels in dental pulp stem cell behavior: the effect of chlorite-oxidized oxyamylose
}

Mostafa EzEldeen ( $\sim$ mostafa.ezeldeen@kuleuven.be)

KU Leuven

Burak Toprakhisar

KU Leuven

Denise Murgia

KU Leuven

Nick Smisdom

Hasselt University

Olivier Deschaume

KU Leuven

Carmen Bartic

KU Leuven

Rafaela Vaz Sousa Pereira

KU Leuven

Ghislain Opdenakker

KU Leuven

Ivo Lambrichts

Hasselt University

Annelies Bronckaers

Hasselt University

Reinhilde Jacobs

KU Leuven

Jennifer Patterson

KU Leuven

Hans Van Oosterwyck

KU Leuven

Research Article 
Keywords: COAM, DPSCs, hydrogels, microstructural, chemokine-binding

Posted Date: December 2nd, 2020

DOI: https://doi.org/10.21203/rs.3.rs-109250/v1

License: (c) (1) This work is licensed under a Creative Commons Attribution 4.0 International License. Read Full License

Version of Record: A version of this preprint was published at Scientific Reports on March 11th, 2021. See the published version at https://doi.org/10.1038/s41598-021-84405-4. 


\section{Abstract}

Tailored hydrogels mimicking the native extracellular environment could aid in overcoming the high variability in regenerative endodontics outcomes. This study aimed to evaluate the effect of the chemokine-binding and antimicrobial polymer, chlorite-oxidized oxyamylose (COAM), on the microstructural properties of fibrin and self-assembling peptide (SAP) hydrogels. Further, to assess the influence of the microstructural differences between the hydrogels on the in vitro behavior of dental pulp stem cells (DPSCs).

Structural and mechanical characterization of the hydrogels with and without COAM was performed by atomic force microscopy and scanning electron microscopy to characterize their microstructure (roughness and fiber length, diameter, straightness and alignment) and by nanoindentation to measure their stiffness (elastic modulus). DPSCs were encapsulated in hydrogels with and without COAM. Cell viability and circularity was determined using confocal microscopy imaging, and proliferation was determined using DNA quantification. Inclusion of COAM did not alter the microstructure of the fibrin hydrogels at the fiber level, while affecting the SAP hydrogel microstructure (homogeneity) leading to fiber aggregation. The stiffness of the SAP hydrogels was 7-fold higher than the fibrin hydrogels. The viability and attachment of DPSCs and DNA content was significantly higher in fibrin hydrogels than in SAP hydrogels. The microstructural stability after COAM inclusion and the favorable DPSCs' response observed in fibrin hydrogels suggest this system as a promising carrier for COAM and for application in endodontic regeneration.

\section{Introduction}

Oral health plays an essential role in our daily lives, contributing to good overall health and wellbeing. Yet, impaired oral conditions have a high prevalence, affecting almost half of the world population ${ }^{1}$. Dental pulp necrosis due to caries, trauma or developmental anomalies is standardly treated by filling the root canal space with bio-inert plastic-like materials, thus depriving the tooth from vascularization, an immune response and innervation. Immature teeth with pulp necrosis are rendered fragile even after treatment, and the roots fail to reach complete development.

Regenerative endodontics has attracted attention attempting to restore tooth vitality ${ }^{2}$. A clinical protocol that intends to reestablish the pulp-dentin complex has been developed, which is known under the synonyms pulp revitalization, root-canal revascularization or regenerative endodontic treatment (RET) ${ }^{3-5}$. This protocol involves the decontamination of the root canal space, followed by intentional laceration of the periapical tissues to form a blood clot matrix within the root canal space. This blood clot combined with endogenous growth factors and stem cells from the apical papillae (SCAPs), induce tooth root maturation through the thickening of the dentinal wall and apical closure ${ }^{3-8}$. Nevertheless, RET has been associated with highly variable outcomes ${ }^{9-11}$, and the histologic studies have shown that true pulp regeneration using the current protocol is difficult to achieve $e^{4,11,12}$. 
Polymeric hydrogels are suitable candidates for tissue engineering and regenerative medicine (TERM) approaches including dental pulp regeneration ${ }^{13}$. The use of tailored hydrogels closely mimicking the native extracellular environment could aid in overcoming the high variability in the RET outcomes. Many recent studies have demonstrated that cell behavior is strongly influenced by the cell microenvironment 14 , which is dictated by the hydrogels' composition and microstructure ${ }^{15,16}$. Polymeric hydrogels can be natural (biopolymers), synthetic or hybrids of the two ${ }^{17,18}$, with several advantages and disadvantages related to each class ${ }^{19}$. Fibrin is a typical natural hydrogel, and it has been extensively used as a biomaterial for different TERM and clinical applications ${ }^{13,18-20}$. Fibrin is a tailorable hydrogel system utilizing fibrinogen, thrombin and Factor XIIla. Fibrinogen, a soluble 340-kDa clotting factor, is enzymatically converted, in the presence of $\mathrm{Ca}^{2+}$, to fibrin monomers by the protease thrombin ${ }^{21}$. These fibrin monomers will undergo self-assembly and lateral aggregation to form protofibrils that are packed into fibers forming branched fibrous networks ${ }^{21}$. Factor XIIla promotes the formation of covalent bonds between fibrinogen peptides to form a mesh network of fibrin fibers ${ }^{18}$. The fibrous network and mechanical properties of fibrin can be tuned by altering the composition ${ }^{22}$. For instance, higher concentrations of factor XIIla result in increasing the stiffness of fibrin by catalyzing fibrin covalent crosslinking and compacting fibers ${ }^{23}$. Moreover, fiber diameter and length are inversely proportional to thrombin concentration ${ }^{18}$, whereas increasing factor XIlla concentrations lead to increased packing of protofibrils within the fibers ${ }^{23}$. Self-assembling peptide (SAP) hydrogels belong to the synthetic class and are produced using amino acids ${ }^{24}$. These peptides self-assemble to form nanofibrous hydrogels in physiological conditions. This self-assembly depends on the specific amino acid sequence of the peptide. These scaffolds consist of $>99 \%$ water, with fibers thought to be around $10 \mathrm{~nm}$ in diameter and 5- 200 $\mathrm{nm}$ pores, closely mimicking the natural extracellular matrix (ECM) ${ }^{24}$. Arginine-alanine-aspartic acidalanine-16 (RADA-16) is a member of the self-assembling peptide family, consisting of 16 residues, and can undergo self-assembly to form nanofibers by forming stable $\beta$-sheet structures within physiological saline, which in turn form an interwoven nanofibrous hydrogel ${ }^{25}$. The SAP (RADA-16) hydrogel has been used in several dental pulp tissue engineering studies with variable degrees of success ${ }^{13,26,27}$.

This study aimed to evaluate the effect of the inclusion of a macromolecule, chlorite-oxidized oxyamylose (COAM), on the microstructural properties of tailored fibrin and SAP hydrogels. COAM is a polyanionic polysaccharide derivative that acts as an antibacterial ${ }^{28}$ and antiviral agent ${ }^{29,30}$ and as an immunomodulator by interference with glycosaminoglycan (GAG) binding of chemokines ${ }^{31}$. Further goals were to assess the influence of the microstructural differences between the hydrogels on the in vitro behavior of dental pulp stem cells (DPSCs) and to identify the most suitable hydrogel for further in vivo experiments.

\section{Results}

COAM did not modify fibrin microstructure, but affected SAP hydrogels leading to fiber aggregation 
Inclusion of COAM did not alter the microstructure of the fibrin hydrogel at the fiber level as demonstrated by AFM images (Figure 1A\&B) (Figure 2A-D) and quantitative analysis (Table 1). SAP hydrogel microstructure (homogeneity) at the fiber level was affected by the inclusion of COAM (Figure 1C\&D) (Figure 2E-H), leading to fiber aggregation. SEM images further confirmed the microstructural stability of the fibrin hydrogels (Figure 1E\&F), whereas the effect of COAM inclusion on the morphology of the SAP hydrogels was not detected by SEM (Figure 1G\&H). The fiber height distribution showed no significant effect of COAM inclusion on fibrin hydrogels (Figure 2A\&B) without COAM and (Figure 2C\&D) with COAM. SAP hydrogels without COAM (Figure 2E\&F) showed a distinct fiber height distribution with three peaks between 1 and $5 \mathrm{~nm}$; after COAM inclusion (Figure 2G\&H) those three peaks disappeared confirming aggregation at the fiber level.

Topographic and quantitative microstructural analysis for the AFM images showed that both fibrin and SAP hydrogels have a nano-fibrous structure at different scales (Table 1). The roughness average (Ra), was 8.1 (SD: 1.6) $\mathrm{nm}$ for fibrin hydrogels and 1.2 (SD: 0.1) nm for the SAP hydrogels. The inclusion of COAM in fibrin increased the Ra to 16.9 (SD: 7.5) nm. However, this increase was not statistically significant $(p>0.05)$. The mean fiber diameter for the fibrin without COAM was $146.6 \pm 1.1 \mathrm{~nm}$ and 156.6 $\pm 1.2 \mathrm{~nm}$ with COAM $(p>0.05)$. The mean fiber diameter for the SAP hydrogels $73.2 \pm 0.3 \mathrm{~nm}$. For the SAP COAM hydrogels the fiber measurements were unreliable due to fiber aggregation (Figure 1D); therefore, this was not reported.

\section{Effect of COAM inclusion on fibrin and SAP hydrogel stiffness}

The elastic modulus for fibrin hydrogels at $3.5 \mathrm{mg} / \mathrm{ml}$ fibrinogen concentration was $752 \pm 13$ Pa before and $683 \pm 6 \mathrm{~Pa}$ after the inclusion of COAM (Figure 3). Furthermore, for the SAP hydrogels at $3.5 \mathrm{mg} / \mathrm{ml}$ RADA-16 concentration, the elastic modulus was $5425 \pm 295 \mathrm{~Pa}$ before and $4821 \pm 386 \mathrm{~Pa}$ after the inclusion of COAM (Figure 3). The stiffness of the SAP hydrogels was 7 -fold higher than the fibrin hydrogels $(p<0.05)$. Inclusion of COAM did not alter the stiffness of the fibrin and SAP hydrogels $(p>$ 0.05).

\section{DPSCs show higher viability and better attachment in fibrin hydrogels}

The viability of the DPSCs in maintenance medium was significantly higher in fibrin hydrogels compared to in SAP hydrogels at each time point $(p<0.05)$ (Figure $4 \mathrm{E})$. The viability did not significantly decrease over time for either the fibrin control hydrogels or fibrin with COAM hydrogels $(p>0.05)$. The average DPSC viability in the fibrin hydrogels was $91.3 \% \pm 0.004$ without and $89.9 \% \pm 0.009$ with COAM over the 7-day test period. On the contrary, the viability declined significantly in the SAP hydrogels without COAM from day $1(66.9 \% \pm 0.03)$ until day $7(54.1 \% \pm 0.02)$ and with COAM from day $1(68.3 \% \pm 0.05)$ until day $7(53.9 \% \pm 0.01)(p<0.05)$ (Figure $4 \mathrm{E})$.

In addition, confocal images (Figure 4A-B) and circularity evaluation (Figure 4F) showed that DPSCs adopt a spread morphology in the fibrin hydrogels both with and without COAM. The average circularity score in the fibrin hydrogels without COAM was $0.25 \pm 0.05$, and $0.26 \pm 0.02$ with COAM, over the 7-day 
test period. In contrast, DPSCs remained rounded in the SAP hydrogels, again in both with and without COAM (Figure 4C-D). The average circularity score in the SAP hydrogels without COAM was $0.76 \pm 0.01$, and $0.74 \pm 0.02$ with COAM, over the 7-day test period. Only hydrogel type had an influence on cellular morphology $(p<0.05)$ indicating superior cell attachment in the fibrin hydrogels (Figure 4F). DPSCs morphology did not change significantly with time for either fibrin or SAP hydrogels with and without COAM (Figure 4F).

\section{DNA quantification}

The DNA quantification of the different cell-laden hydrogels showed significantly higher DNA content in fibrin hydrogels compared to the SAP hydrogels $(p<0.05)$ (Figure 5). The ANOVA model showed a statistically significant relationship between the hydrogel type and the presence of COAM and the amount of DNA quantified $(p<0.05)$. DPSCs showed a proliferative pattern in fibrin hydrogels with an average 1.3-fold increase in DNA content at day 7 compared to day 0 for fibrin without COAM $(p>0.05)$ and a significant 2.1-fold increase for fibrin with $\operatorname{COAM}(p<0.05)$.

A low DNA content was observed in SAP hydrogels without COAM at day 0 with 10-fold and 8-fold lower DNA content compared to the fibrin hydrogels without COAM $(p<0.05)$ and SAP hydrogels with COAM $(p$ $>0.05$ ). SAP hydrogels with COAM showed higher DNA content than SAP hydrogels without COAM ranging between 5 -fold higher at day 1 and 3-fold higher at day 7. However, these differences were not statistically significant $(p>0.05)$. Moreover, the DNA content was stable in both SAP hydrogels from day 1 up to day 7 (Figure 5).

\section{Discussion}

This study characterized the structural and mechanical characteristics of selected compositions of fibrin and SAP hydrogels. Nano- to micro-scale structural and mechanical cues are associated with biological responses, in both native ECM and synthetic constructs ${ }^{14}$. Although the understanding of the association between the surface topography and the cellular response is still limited, it has been suggested that the nano-topography enhances cellular communication in neural cell networks ${ }^{32}$ and protein adsorption affecting the modulation of cellular interactions ${ }^{33}$. In this study, the nano-scale topographical features of fibrin and SAP hydrogels were different. The roughness average of the fibrin surface was 7 -fold higher than the SAP hydrogel and with a 2-fold increase in the average fiber diameter. Other features, such as fiber straightness and alignment, were comparable. Fibrin hydrogels showed structural stability after the inclusion of our experimental macromolecule, COAM, while SAP hydrogels were affected leading to fiber aggregation. The effect of COAM inclusion on the SAP hydrogels was not observed in the SEM images, which could be due to the sample preparation procedure that results in drying artifacts.

The measured stiffness of fibrin hydrogels, with the composition tested in the current study, was in the range of the previously reported values for the stiffness of the native pulp tissue, which has been reported to be $800 \mathrm{~Pa}^{34}$. In addition, the stiffness of SAP hydrogels was found to be 7 -fold higher than the fibrin 
hydrogels. DPSCs are mesenchymal stem/stromal cells (MSCs) that pose the potential to differentiate into numerous cell types in vitro including odontoblasts/osteoblasts, chondroblasts, adipocytes and neuronal-like cells ${ }^{35-37}$. MSCs have been shown to specify lineage and commit to phenotypes with extreme sensitivity to tissue-level elasticity ${ }^{38}$, as soft matrices induced neurogenic differentiation and stiffer matrices were osteogenic ${ }^{38}$. The current results might aid in explaining the observations of Hilkens et al. ${ }^{26}$, who reported mineralized tissue formation within SAP (RADA-16) hydrogels encapsulating DPSCs when implanted in an ectopic mouse model for 12 weeks. Future studies should explore to which extent differences in matrix stiffness would affect DPSC differentiation profiles in vivo.

The current study showed higher DPSC survival in fibrin hydrogels compared to in SAP hydrogels. This agrees with the data reported by Galler et al. ${ }^{13}$, where DPSCs in fibrin hydrogels at $10 \mathrm{mg} / \mathrm{ml}$ showed higher viability compared to DPSCs in SAP (RADA-16) hydrogels when evaluated using an MTT assay. Moreover, Dissanayaka et al. ${ }^{39}$ reported DPSCs' survival at day 4 of just above $60 \%$ in SAP (RADA-16) hydrogels at $1.5 \mathrm{mg} / \mathrm{ml}$, reflecting the data reported in the current study. The higher cell survival in fibrin hydrogels can be likely explained by the presence of natural cell adhesion motives ${ }^{40}$ facilitating cell attachment and elongated cellular morphology, which was demonstrated in the current study, while SAP hydrogels lack these cell adhesion motifs. Future studies could explore improving cellular attachment to SAP hydrogels by conjugating bioactive short peptide motives such as the integrin-binding arginineglycine-aspartic acid (RGD) to the C-terminus of the RADA-16 peptide. Another possible explanation could be the initial acidic $\mathrm{pH}$ (3.0) of the SAP hydrogels that is only neutralized after addition of medium to induce gelation. Differences in cell viabilities were confirmed by the DNA quantification results, with a 10fold lower DNA content measured at day 0 for SAP hydrogels compared to fibrin hydrogels. The DNA content in SAP hydrogels with COAM was 8-fold and 5-fold higher compared to SAP hydrogels without COAM at day 0 and day 1 , respectively, suggesting an initial protective influence for COAM that needs to be further investigated. DPSCs' viability and the DNA content for the SAP hydrogels with and without COAM was then relatively stable over the remaining period of the experiments, which strengthens the hypothesis that this drop in viability is related to the low attachment and the $\mathrm{pH}$ conditions at the time of encapsulation.

One interesting outcome was the effect of COAM on the increase of the DNA content. Such effect for the presence of COAM may be explained in terms of a biological influence since no effect was observed for COAM inclusion on the structural and mechanical properties of the fibrin hydrogels. COAM is a polyanionic polysaccharide derivative with an antibacterial ${ }^{28}$ and a broad-spectrum antiviral activity that acts as an immunomodulator 29,30 . COAM induces and binds chemokines such as granulocyte chemotactic protein-2 (GCP-2) leading to significant recruitment of myeloid cells in mice ${ }^{41}$. Furthermore, it has been demonstrated that COAM competes with glycosaminoglycans (GAGs) for binding and recruitment of chemokines ${ }^{31}$. This COAM-chemokine binding complex influenced chemokine localization and selectivity of leukocyte responses and migration ${ }^{31}$. DPSCs and MSCs produce a plethora of soluble factors, cytokines and chemokines influencing cellular growth, proliferation, migration, differentiation and 
immune responses ${ }^{42,43}$. For example, insulin-like growth factor-1 (IGF-1), a cytokine produced by DPSCs, was found to stimulate DPSCs' proliferation in serum-free culture medium ${ }^{44}$. Moreover, DPSCs overexpressing the chemokine stromal-derived factor-1 alpha (SDF-1a/CXCL12) showed higher cell proliferation compared to wild-type DPSCs ${ }^{45}$. Therefore, one possible explanation for the higher DNA content in fibrin hydrogels with COAM could be the formation of a binding complex increasing the availability of factors and chemokines involved in cellular proliferation inside the 3D hydrogel microenvironment, which is in line with preliminary experiments, in which we found that COAM binds SDF-1a/CXCL12, both on solid phase and in solution (unpublished data).

Finally, the current study presents a comprehensive structural and mechanical characterization for two promising biomaterials for dental pulp tissue engineering in combination with an analysis of biological features such viability, cell shape and proliferation. Future research will explore the influence of different hydrogel properties such as matrix stiffness on DPSC migration and differentiation. Furthermore, the molecular mechanisms underlying the effect of COAM on DPSCs' proliferation need to be investigated in detail in order to obtain insights to optimize their use in tissue engineering.

\section{Conclusion}

The microstructural stability after the inclusion of COAM, the preservation of cell viability, elongated morphology and higher DNA content observed in the fibrin hydrogels suggests this system as a promising carrier for COAM and for application in endodontic regeneration.

\section{Materials And Methods}

All methods were performed in accordance with the relevant guidelines and regulations.

\section{Structural and Mechanical Characterization}

\section{Hydrogel composition and preparation}

Fibrin hydrogels were prepared by mixing fibrinogen and thrombin components in equal volumes $(\mathrm{pH}=$ 6.6), as described previously ${ }^{18}$. Plasminogen-depleted fibrinogen (Enzyme Research Laboratories, USA), derived from human plasma, was dissolved in $20 \mathrm{mM} \mathrm{HEPES}$ and $150 \mathrm{mM} \mathrm{NaCl}$ (fibrinogen buffer).

Sterile stock solutions of thrombin (Sigma, USA), derived from human plasma, and factor XIII

(Fibrogammin, CSL Behring, Germany) were prepared in $20 \mathrm{mM} \mathrm{HEPES}, 150 \mathrm{mM} \mathrm{NaCl}, 40 \mathrm{mM} \mathrm{CaCl} 2$ and $0.1 \%$ BSA (thrombin buffer). Thrombin and factor XIII were mixed with the thrombin buffer and were kept in a water bath at $37^{\circ} \mathrm{C}$ for $30 \mathrm{~min}$ in order to activate factor XIII to factor XIIla. The control fibrin hydrogels were prepared at $3.5 \mathrm{mg} / \mathrm{ml}$ fibrinogen, $0.1 \mathrm{U} / \mathrm{ml}$ thrombin and $0.1 \mathrm{U} / \mathrm{ml}$ factor XIII, whereas the test fibrin hydrogels were prepared at $3.5 \mathrm{mg} / \mathrm{ml}$ fibrinogen, $0.1 \mathrm{U} / \mathrm{ml}$ thrombin, $0.1 \mathrm{U} / \mathrm{ml}$ factor $\mathrm{XIII}$ and 1 $\mathrm{mg} / \mathrm{ml}$ COAM. 
SAP RADA-16 hydrogels were prepared according to the manufacturer's instructions by mixing the peptide solution (PuraMatrixÔ Peptide Hydrogel; BD Biosciences, USA) with $20 \%$ sucrose solution followed by adding an equal amount of phosphate buffered saline (PBS) for gelation. The control SAP hydrogels were prepared at $3.5 \mathrm{mg} / \mathrm{ml}$ RADA-16 peptide, whereas the test SAP hydrogels were prepared at $3.5 \mathrm{mg} / \mathrm{ml}$ RADA-16 peptide and $1 \mathrm{mg} / \mathrm{ml}$ COAM.

COAM was synthesized by a two-step oxidation of amylose, purified and fractionated according to molecular weight (MW) as described previously ${ }^{29,46}$. COAM was endotoxin-free and used as MW mixture (corresponding to protein molecular equivalent weights exceeding $100 \mathrm{kDa}$ ).

\section{Atomic force microscopy (AFM)}

AFM imaging was performed to characterize the microstructure of the different hydrogels at the fiber level. A $100 \mathrm{ml}$ sample from each hydrogel composition $(n=3)$ was deposited on a silica sample holder and incubated at $37^{\circ} \mathrm{C}$ for $30 \mathrm{~min}$. After gelation, the top surface of the hydrogel was carefully removed using gentle air blowing/drying to allow the imaging of the inner network. Agilent 5500 with MAC III controller and JPK Nanowizard 3 AFM systems were used for morphological imaging in intermittent contact mode in air. A sharp microlever probe MSNL-F ( $f=120 \mathrm{kHz}, \mathrm{k}=0.6 \mathrm{~N} / \mathrm{m}$, tip radius of curvature < $12 \mathrm{~nm}$ ) was used. The AFM topography images were leveled, line-corrected and measured (height and roughness profiles) using Gwyddion ${ }^{47}$. A fiber extraction algorithm, ct-FIRE ${ }^{48}$, was applied to the AFM images to characterize the fiber diameter, length, straightness and alignment.

\section{Scanning electron microscopy (SEM)}

A $100 \mathrm{ml}$ sample from each hydrogel composition $(n=3)$ was prepared then fixed using $4 \%$ glutaraldehyde in PBS for 30 min. This was followed by drying in an ethanol series for the fibrin hydrogels and freeze-drying for the SAP hydrogels because the SAP hydrogels disintegrated in ethanol. Subsequently, the samples were attached to aluminum stubs and sputter coated with a $5 \mathrm{~nm}$ thick platinum layer under vacuum. The microstructure was then observed using a XL30 FEG scanning electron microscope (Philips, Panama).

\section{Evaluation of hydrogel stiffness}

The stiffness of hydrogels of each composition $(n=3)$ was determined using a Chiaro Nanoindenter (Optics11, the Netherlands) by applying serial indentations with a spherical glass probe $(r=24.5 \mu \mathrm{m})$ attached to flexible cantilever $(\mathrm{k}=0.063 \mathrm{~N} / \mathrm{m})$. Loading and unloading velocities of the probe were set to $2 \mu \mathrm{m} / \mathrm{s}$, with $2 \mathrm{~s}$ of holding period in between. For each individual sample, matrix scans ( $5 \times 5$ points) from three random locations were obtained. Load vs. displacement curves were extracted individually for each indentation point, and the Elastic Modulus (E) was calculated by using a Hertzian Contact Model (Poisson's ratio $=0.5$ ) with Piuma Dataviewer Software (Optics11, the Netherlands), using equation (1): 
$F=\frac{4}{3} * E * \sqrt{R} * h^{3 / 2} *\left(1-\vartheta^{2}\right)$

where $F$ is the applied force, $E$ is the elastic modulus, $R$ is the radius of the probe, $h$ is the indentation depth, and $\vartheta$ is Poisson's ratio.

\section{Biological Characterization}

\section{Primary cell cultures}

Dental pulp tissues were acquired with informed consent from patients (15-20 years of age, male and female) undergoing extraction of third molars for therapeutic or orthodontic reasons as described previously ${ }^{49}$. Written informed consent was obtained from the patients or their parents, as approved by the medical ethical committee of Hasselt University, Belgium (protocol 13/0104U). The dental pulp tissue was harvested with forceps after mechanically fracturing the disinfected tooth with surgical chisels. Pulp tissues were then rinsed and transported at $37^{\circ} \mathrm{C}$ in Eagle's Minimal Essential Medium, alpha modification (aMEM, Sigma-Aldrich, USA) supplemented with 2 mM L-glutamine (Sigma-Aldrich), 100 $\mathrm{U} / \mathrm{ml}$ penicillin (Sigma-Aldrich), $100 \mu \mathrm{g} / \mathrm{ml}$ streptomycin (Sigma-Aldrich) and 10\% fetal bovine serum (FBS, Gibco, ThermoFisher Scientific, USA). DPSCs were isolated according to the explant method and expanded in culture as described previously ${ }^{49}$. Cells were cultured in a-MEM, enriched with $10 \%$ heatinactivated foetal bovine serum (FBS, Biowest, Nuaillé, France), $2 \mathrm{mM}$ I-glutamine, $100 \mathrm{U} / \mathrm{mL}$ penicillin and $100 \mu \mathrm{g} / \mathrm{mL}$ streptomycin (Sigma-Aldrich). Only mycoplasma negative cells, screened with the PlasmoTest ${ }^{\mathrm{TM}}$ kit (InvivoGen), were used. All DPSC cultures were tested for the expression of the following (stem) cell markers at the protein level by means of flow cytometry as described previously 49 : positive for CD29,CD73, CD90 and CD105 and negative for CD31, CD34 and CD45.

\section{Evaluation of DPSC viability}

To obtain enhanced fluorescent protein (eGFP) labelled cells, pooled DPSCs from three donors were transduced with a lentiviral vector encoding eGFP and a blasticidin resistance cassette. Selection was performed with blasticidin ( $10 \mu \mathrm{g} / \mathrm{mL}$, InvivoGen, Toulouse, France). Stem cells were used until passage 15. These labelled DPSCs at $1 \times 10^{6} \mathrm{cells} / \mathrm{ml}$ seeding density were encapsulated in $100 \mathrm{ml}$ hydrogels $(n=9)$ with and without COAM and deposited in a glass bottom 96 well plate (CELLview slide, Greiner, Austria). After gelation, an equal amount of maintenance culture medium was added (aMEM supplemented with 2 $\mathrm{mM} \mathrm{L-glutamine,} 100 \mathrm{U} / \mathrm{ml}$ penicillin, $100 \mu \mathrm{g} / \mathrm{ml}$ streptomycin and $1 \% \mathrm{FBS}$ ). Tranexamic acid at 0.5 $\mathrm{mg} / \mathrm{ml}$ (Exacyl, Eumedica, Belgium) was added to the medium of fibrin hydrogels to prevent fibrin degradation. After 1, 4 and 7 days in culture, the nucleus of the cells was labelled with Hoechst 33342 (Invitrogen, USA), and the dead DPSCs were labelled using the nucleic acid dye propidium iodide (PI) (Invitrogen) according to the manufacturer's instructions using an incubation for $15 \mathrm{~min}$ at $37^{\circ} \mathrm{C}$. The images were collected using laser scanning confocal microscopy (LSM 880, Zeiss, Germany) using a 20x 
objective (EC Plan-Neofluar 20x/0.50 M27). The fluorescence excitation/emission was measured at 490/552, 597/695 and 410/490 nm for GFP, PI and Hoechst 33342, respectively. The number of live cells and dead cells were analyzed from 5 different regions per well $(425 \mathrm{~mm} \times 425 \mathrm{~mm} \times 10 \mathrm{~mm})$ in Fiji (Image J, National Institutes of Health, USA) ${ }^{50}$. Viability was calculated as a percent of live cells among the total number of live and dead cells.

\section{Evaluation of DPSC circularity (shape analysis)}

Live cells from 5 different regions per well $(425 \mathrm{~mm} \times 425 \mathrm{~mm} \times 10 \mathrm{~mm}$ ) were segmented using a combination of watershed segmentation, thresholding and manual contour correction for cell boundaries. Shape (circularity) of segmented cells per region, excluding cells on the image edges, was analyzed using the particle analysis plug-in in Fiji (Image $\mathrm{J}$, National Institutes of Health, USA) ${ }^{50}$. The circularity score was averaged for each well yielding a final circularity score ranging between 0 and 1 , where the closer the score to 1 , the closer the shape to a circle, which would indicate poor cellular attachment.

\section{Evaluation of DPSC proliferation (PicoGreen/Quant-iT DNA Quantification)}

DPSCs at $5 \times 10^{5}$ cells $/ \mathrm{ml}$ seeding density were encapsulated in $100 \mathrm{ml}$ hydrogels $(n=3$ per gel and per time point) with and without COAM and deposited in a 96 well plate coated with $50 \mathrm{ml}$ of the same hydrogel devoid of cells or COAM (TPP tissue culture plates, Sigma-Aldrich, USA). Hydrogels devoid of cells as blank replicates were prepared. In addition, 2D controls of $5 \times 10^{3}$ cells were seeded in a 96 well plate. After gelation an equal amount of serum free mesenchymal stem cell (MSC) medium (MesenCultôACF plus medium, Stem Cell Technologies, Canada) supplemented with $2 \mathrm{mM} \mathrm{L-glutamine,} 100 \mathrm{U} / \mathrm{ml}$ penicillin and $100 \mu \mathrm{g} / \mathrm{ml}$ streptomycin was added to each well. At baseline (day 0 ) and after 1, 2, 3 and 7 days in culture, a PicoGreen/Quant-iT kit (Invitrogen) was used to investigate the effect of different hydrogels on cellular proliferation. The DNA content of three hydrogels per condition and per time point was calculated for three independent experiments. Fibrin hydrogels were first digested in a buffer composed of $50 \mathrm{FU} / \mathrm{ml}$ nattokinase in $5 \mathrm{mM}$ EDTA in PBS for $2 \mathrm{~h}$ at $37^{\circ} \mathrm{C}$. SAP hydrogels were digested in a buffer composed of $1 \mathrm{mg} / \mathrm{ml}$ Pronase (Thermo Fisher Scientific, USA) in PBS for $2 \mathrm{~h}$ at $37^{\circ} \mathrm{C}$. The cells seeded in the control wells were released using Trypsin-EDTA. The contents of the wells were collected, and cell pellets were retrieved by centrifugation. Retrieved cell pellets were then lysed to extract DNA using $100 \mathrm{ml}$ cell lysis buffer composed of $0.029 \%$ Sodium EDTA, $0.112 \%$ Sodium pyrophosphate decahydrate, $0.88 \%$ Sodium chloride, $0.315 \%$ Tris $\mathrm{HCl}, 1 \%$ Triton-X-100, 0.038\% EGTA, $0.0001 \%$ Leupeptin, 0.019\% Sodium orthovanadate, $0.0216 \%$-glycerophosphate and 1mM PMSF (ab152163, Abcam) and centrifuged at $14000 \mathrm{rpm}$ at $4^{\circ} \mathrm{C}$ to collect the supernatant. A $200 \mathrm{ml}$ working solution representing each well (hydrogel) was prepared and aliquoted directly into black 96-well plates (Chimney well, FluotracÔ, Greiner, Austria), according to the manufacturer's instructions, and incubated for 5 min protected from light at room temperature. The fluorescence excitation/emission was measured at 481/520 nm using a microplate reader (VarioskanÔ, Thermo Fisher Scientific, USA). A standard curve was performed with IDNA, provided with the kit and treated equally to the sample plates. The standards ranged from $10 \mathrm{ng} / \mathrm{ml}$ to $1 \mathrm{mg} / \mathrm{ml}$ IDNA and were used to calculate the final DNA content per $\mathrm{ml}$ of sample. 


\section{Statistical analysis}

Statistical analysis was performed using the statistical software package GraphPad Prism 8.00 (GraphPad Software, La Jolla California USA). Comparison of the fiber measurements from AFM images was performed using a one-way analysis of variance (ANOVA). Comparison of the stiffness of the hydrogels was performed using a two-way ANOVA. The influence of the different experimental conditions and the time factor on cell viability, shape and DNA quantity was modeled using a three-way ANOVA. All ANOVA tests were followed by Tukey's correction for multiple comparisons. Statistical significance was determined at $p<0.05$. Descriptive statistics are represented as mean and standard deviation (SD), or standard error of mean $( \pm)$, where appropriate.

\section{Declarations}

\section{Acknowledgements}

Supported by the Fund for Scientific Research-Flanders (FWO-Vlanderen) grant number (G089213N), Research Council of KU Leuven grant numbers (C24/18/068), (C14/17/111), and KU Leuven equipment grant (KA/16/084).

The authors deny any conflicts of interest related to this study.

\section{Author Contributions}

M.E., B.T., R.J., and J.P. contributed to conception, design, data acquisition, analysis, and interpretation, drafted and critically revised the manuscript; D.M., O.D., G.O., I.L., A.B., contributed to data acquisition, analysis, and interpretation, critically revised the manuscript; N.S., C.B., H.V., and R.P., contributed to contributed to conception and design, critically revised the manuscript. All authors gave final approval and agree to be accountable for all aspects of the study.

\section{References}

1 Kassebaum, N. J. et al. Global, Regional, and National Prevalence, Incidence, and Disability-Adjusted Life Years for Oral Conditions for 195 Countries, 1990-2015: A Systematic Analysis for the Global Burden of Diseases, Injuries, and Risk Factors. J Dent Res96, 380-387, doi:10.1177/0022034517693566 (2017).

2 Galler, K. M. \& D'Souza, R. N. Tissue engineering approaches for regenerative dentistry. Regen Med6, 111-124, doi:10.2217/rme.10.86 (2011).

3 Chueh, L. H. \& Huang, G. T. Immature teeth with periradicular periodontitis or abscess undergoing apexogenesis: a paradigm shift. J Endod32, 1205-1213, doi:10.1016/j.joen.2006.07.010 (2006).

4 Huang, G. T. \& Garcia-Godoy, F. Missing Concepts in De Novo Pulp Regeneration. J.Dent.Res.93, 717724, doi:0022034514537829 [pii];10.1177/0022034514537829 [doi] (2014). 
5 Chueh, L. H. et al. Regenerative endodontic treatment for necrotic immature permanent teeth. $J$ Endod35, 160-164, doi:10.1016/j.joen.2008.10.019 (2009).

6 Albuquerque, M. T., Valera, M. C., Nakashima, M., Nor, J. E. \& Bottino, M. C. Tissue-engineering-based strategies for regenerative endodontics. J Dent Res93, 1222-1231, doi:10.1177/0022034514549809 (2014).

7 Huang, G. T. et al. The hidden treasure in apical papilla: the potential role in pulp/dentin regeneration and bioroot engineering. J Endod34, 645-651, doi:10.1016/j.joen.2008.03.001 (2008).

8 Murray, P. E., Garcia-Godoy, F. \& Hargreaves, K. M. Regenerative endodontics: a review of current status and a call for action. J Endod33, 377-390, doi:10.1016/j.joen.2006.09.013 (2007).

9 EzEldeen, M., Van Gorp, G., Van Dessel, J., Vandermeulen, D. \& Jacobs, R. 3-dimensional analysis of regenerative endodontic treatment outcome. J Endod41, 317-324, doi:10.1016/j.joen.2014.10.023 (2015).

10 Meschi, N., EzEldeen, M., Torres Garcia, A. E., Jacobs, R. \& Lambrechts, P. A Retrospective Case Series in Regenerative Endodontics: Trend Analysis Based on Clinical Evaluation and 2- and 3-dimensional Radiology. J Endod44, 1517-1525, doi:10.1016/j.joen.2018.06.015 (2018).

11 Meschi, N. et al. Regenerative Endodontic Procedures Posttrauma: Immunohistologic Analysis of a Retrospective Series of Failed Cases. J Endod45, 427-434, doi:10.1016/j.joen.2019.01.007 (2019).

12 Austah, O. et al. Comprehensive Characterization of 2 Immature Teeth Treated with Regenerative Endodontic Procedures. J Endod44, 1802-1811, doi:10.1016/j.joen.2018.09.007 (2018).

13 Galler, K. M. et al. Suitability of Different Natural and Synthetic Biomaterials for Dental Pulp Tissue Engineering. Tissue Eng Part A24, 234-244, doi:10.1089/ten.TEA.2016.0555 (2018).

14 Betancourt, B. A. P. et al. Effect of the scaffold microenvironment on cell polarizability and capacitance determined by probabilistic computations. Biomed Mater13, 025012, doi:10.1088/1748605X/aa9650 (2018).

15 Lin, S., Sangaj, N., Razafiarison, T., Zhang, C. \& Varghese, S. Influence of physical properties of biomaterials on cellular behavior. Pharm Res28, 1422-1430, doi:10.1007/s11095-011-0378-9 (2011).

16 Man, A. J., Davis, H. E., Itoh, A., Leach, J. K. \& Bannerman, P. Neurite outgrowth in fibrin gels is regulated by substrate stiffness. Tissue Eng Part A17, 2931-2942, doi:10.1089/ten.tea.2011.0030 (2011).

17 Galler, K. M., Hartgerink, J. D., Cavender, A. C., Schmalz, G. \& D'Souza, R. N. A customized selfassembling peptide hydrogel for dental pulp tissue engineering. Tissue Eng Part A18, 176-184, doi:10.1089/ten.TEA.2011.0222 (2012). 
18 Leonidakis, K. A. et al. Fibrin structural and diffusional analysis suggests that fibers are permeable to solute transport. Acta Biomater47, 25-39, doi:10.1016/j.actbio.2016.09.044 (2017).

19 Yuan, Z. et al. Biomaterial selection for tooth regeneration. Tissue Eng Part B Rev17, 373-388, doi:10.1089/ten.TEB.2011.0041 (2011).

20 Sierra, D. H. Fibrin sealant adhesive systems: a review of their chemistry, material properties and clinical applications. J Biomater App/, 309-352, doi:10.1177/088532829300700402 (1993).

21 Weisel, J. W. \& Litvinov, R. I. Mechanisms of fibrin polymerization and clinical implications. Blood121, 1712-1719, doi:10.1182/blood-2012-09-306639 (2013).

22 Litvinov, R. I. \& Weisel, J. W. Fibrin mechanical properties and their structural origins. Matrix Bio/60-61, 110-123, doi:10.1016/j.matbio.2016.08.003 (2017).

23 Kurniawan, N. A., Grimbergen, J., Koopman, J. \& Koenderink, G. H. Factor XIII stiffens fibrin clots by causing fiber compaction. J Thromb Haemost12, 1687-1696, doi:10.1111/jth.12705 (2014).

24 Cui, H., Webber, M. J. \& Stupp, S. I. Self-assembly of peptide amphiphiles: from molecules to nanostructures to biomaterials. Biopolymers94, 1-18, doi:10.1002/bip.21328 (2010).

25 Gelain, F., Horii, A. \& Zhang, S. Designer self-assembling peptide scaffolds for 3-d tissue cell cultures and regenerative medicine. Macromol Bioscl7, 544-551, doi:10.1002/mabi.200700033 (2007).

26 Hilkens, P. et al. The Angiogenic Potential of DPSCs and SCAPs in an In Vivo Model of Dental Pulp Regeneration. Stem Cells Int2017, 2582080, doi:10.1155/2017/2582080 (2017).

27 Mangione, F. et al. Implanted Dental Pulp Cells Fail to Induce Regeneration in Partial Pulpotomies. J Dent Res96, 1406-1413, doi:10.1177/0022034517725523 (2017).

$28 \mathrm{Zi}$, Y. et al. Effects of carboxyl and aldehyde groups on the antibacterial activity of oxidized amylose. Carbohydr Polym192, 118-125, doi:10.1016/j.carbpol.2018.03.060 (2018).

29 Li, S., Martens, E., Dillen, C., Van den Steen, P. E. \& Opdenakker, G. Virus entry inhibition by chloriteoxidized oxyamylose versus induction of antiviral interferon by poly(l:C). Biochem Pharmaco/76, 831-840, doi:10.1016/j.bcp.2008.07.022 (2008).

30 Opdenakker, G., Li, S., Berghmans, N. \& Damme, J. V. in Carbohydrate ChemistryCarbohydrate Chemistry 1-12 (2012).

$31 \mathrm{Li}, \mathrm{S}$. et al. Interference with glycosaminoglycan-chemokine interactions with a probe to alter leukocyte recruitment and inflammation in vivo. PLoS One9, e104107, doi:10.1371/journal.pone.0104107 (2014).

32 Onesto, V. et al. Nano-topography Enhances Communication in Neural Cells Networks. Sci Rep7, 9841, doi:10.1038/s41598-017-09741-w (2017). 
33 Lord, M. S., Foss, M. \& Besenbacher, F. Influence of nanoscale surface topography on protein adsorption and cellular response. Nano Today5, 66-78, doi:10.1016/j.nantod.2010.01.001 (2010).

34 Erisken, C., Kalyon, D. M., Zhou, J., Kim, S. G. \& Mao, J. J. Viscoelastic Properties of Dental Pulp Tissue and Ramifications on Biomaterial Development for Pulp Regeneration. J Endod41, 1711-1717, doi:10.1016/j.joen.2015.07.005 (2015).

35 Bronckaers, A. et al. Angiogenic properties of human dental pulp stem cells. PLoS One8, e71104, doi:10.1371/journal.pone.0071104 (2013).

36 Bronckaers, A. et al. Mesenchymal stem/stromal cells as a pharmacological and therapeutic approach to accelerate angiogenesis. Pharmacol Ther143, 181-196, doi:10.1016/j.pharmthera.2014.02.013 (2014).

37 Ratajczak, J. et al. Angiogenic Capacity of Periodontal Ligament Stem Cells Pretreated with Deferoxamine and/or Fibroblast Growth Factor-2. PLoS One11, e0167807, doi:10.1371/journal.pone.0167807 (2016).

38 Engler, A. J., Sen, S., Sweeney, H. L. \& Discher, D. E. Matrix elasticity directs stem cell lineage specification. Cel/126, 677-689, doi:10.1016/j.cell.2006.06.044 (2006).

39 Dissanayaka, W. L., Hargreaves, K. M., Jin, L., Samaranayake, L. P. \& Zhang, C. The interplay of dental pulp stem cells and endothelial cells in an injectable peptide hydrogel on angiogenesis and pulp regeneration in vivo. Tissue Eng Part A21, 550-563, doi:10.1089/ten.TEA.2014.0154 (2015).

40 Li, Y., Meng, H., Liu, Y. \& Lee, B. P. Fibrin gel as an injectable biodegradable scaffold and cell carrier for tissue engineering. ScientificWorld Journa/2015, 685690, doi:10.1155/2015/685690 (2015).

$41 \mathrm{Li}, \mathrm{S}$. et al. Myeloid cells are tunable by a polyanionic polysaccharide derivative and co-determine host rescue from lethal virus infection. J Leukoc Bio/88, 1017-1029, doi:10.1189/jlb.1109724 (2010).

42 Joo, K. H. et al. Cytokine Expression of Stem Cells Originating from the Apical Complex and Coronal Pulp of Immature Teeth. J Endod44, 87-92 e81, doi:10.1016/j.joen.2017.08.018 (2018).

43 Lavoie, J. R. \& Rosu-Myles, M. Uncovering the secretes of mesenchymal stem cells. Biochimie95, 2212-2221, doi:10.1016/j.biochi.2013.06.017 (2013).

44 Onishi, T., Kinoshita, S., Shintani, S., Sobue, S. \& Ooshima, T. Stimulation of proliferation and differentiation of dog dental pulp cells in serum-free culture medium by insulin-like growth factor. Arch Oral Bio/44, 361-371, doi:10.1016/s0003-9969(99)00007-2 (1999).

45 Zhu, L., Dissanayaka, W. L. \& Zhang, C. Dental pulp stem cells overexpressing stromal-derived factor1alpha and vascular endothelial growth factor in dental pulp regeneration. Clin Oral Investig23, 24972509, doi:10.1007/s00784-018-2699-0 (2019). 
46 Claes, P. et al. Polyacetal carboxylic acids: a new group of antiviral polyanions. J Viro/5, 313-320, doi:10.1128/JVI.5.3.313-320.1970 (1970).

47 Nečas, D. \& Klapetek, P. Gwyddion: an open-source software for SPM data analysis. Open Physics10, doi:10.2478/s11534-011-0096-2 (2012).

48 Bredfeldt, J. S. et al. Computational segmentation of collagen fibers from second-harmonic generation images of breast cancer. J Biomed Opt19, 16007, doi:10.1117/1.JBO.19.1.016007 (2014).

49 Hilkens, P. et al. Effect of isolation methodology on stem cell properties and multilineage differentiation potential of human dental pulp stem cells. Cell Tissue Res353, 65-78, doi:10.1007/s00441013-1630-x (2013).

50 Schindelin, J. et al. Fiji: an open-source platform for biological-image analysis. Nat Methods 9 , 676682, doi:10.1038/nmeth.2019 (2012).

\section{Tables}

Table 1: AFM image analysis using ctFIRE Fiber Extraction Algorithm

\begin{tabular}{|c|c|c|c|c|}
\hline Parameter & Fibrin & Fibrin COAM & SAP & SAP COAM \\
\hline Roughness average (Ra) & $\begin{array}{l}8.1 \mathrm{~nm} \\
\text { (SD: } 1.6)\end{array}$ & $\begin{array}{l}16.9 \text { nm } \\
(S D: 7.5)\end{array}$ & $\begin{array}{l}1.2 \mathrm{~nm} \\
(\mathrm{SD}: 0.1)\end{array}$ & $\begin{array}{l}3.0 \text { nm } \\
\text { (SD: } 0.4)\end{array}$ \\
\hline Fiber diameter & $\begin{array}{l}146.6 \mathrm{~nm}{ }^{\star \star} \\
( \pm 1.1)\end{array}$ & $\begin{array}{l}156.6 \mathrm{~nm}^{\star \star} \\
( \pm 1.2)\end{array}$ & $\begin{array}{l}73.3 n m^{\star \star} \\
( \pm 0.3)\end{array}$ & NA \\
\hline Fiber length & $\begin{array}{l}1136.7 \mathrm{~nm} \\
( \pm 50.2)\end{array}$ & $\begin{array}{l}1077.7 \mathrm{~nm} \\
( \pm 49.0)\end{array}$ & $\begin{array}{l}1369.9 \mathrm{~nm} \\
( \pm 24.7)\end{array}$ & NA \\
\hline Fiber straightness & $\begin{array}{l}0.93 \\
( \pm 0.003)\end{array}$ & $\begin{array}{l}0.93 \\
( \pm 0.002)\end{array}$ & $\begin{array}{l}0.80 \\
( \pm 0.003)\end{array}$ & NA \\
\hline Fiber alignment & 0.05 & 0.06 & 0.06 & NA \\
\hline
\end{tabular}

SD: Standard deviation

\pm : Standard Error of Mean

*: measured on the aggregated fibers

**: approximately overestimated by $15 \mathrm{~nm}$ because of tip diameter

NA: not available because fiber aggregation rendered measurements unreliable 


\section{Figures}
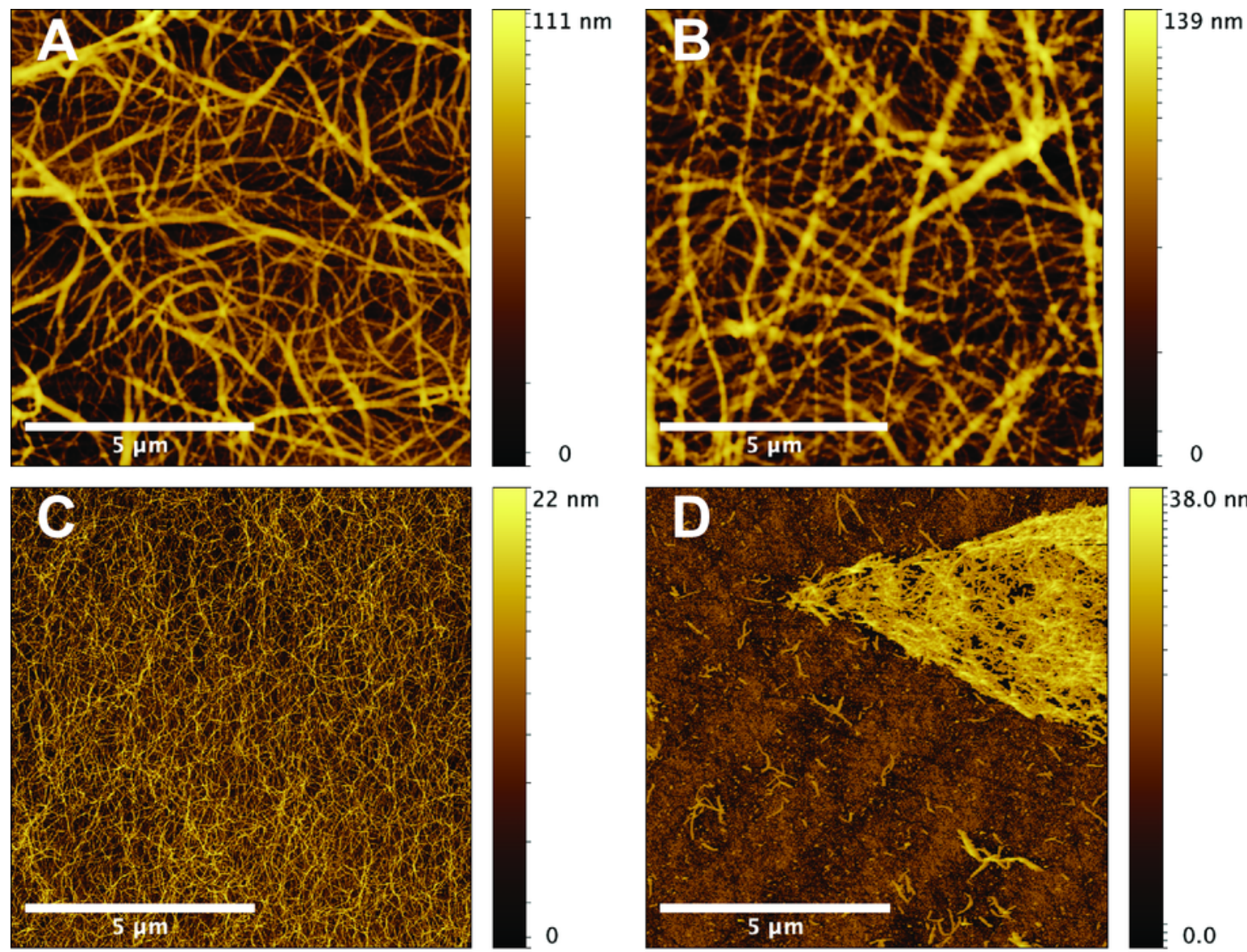

$=38.0 \mathrm{~nm}$
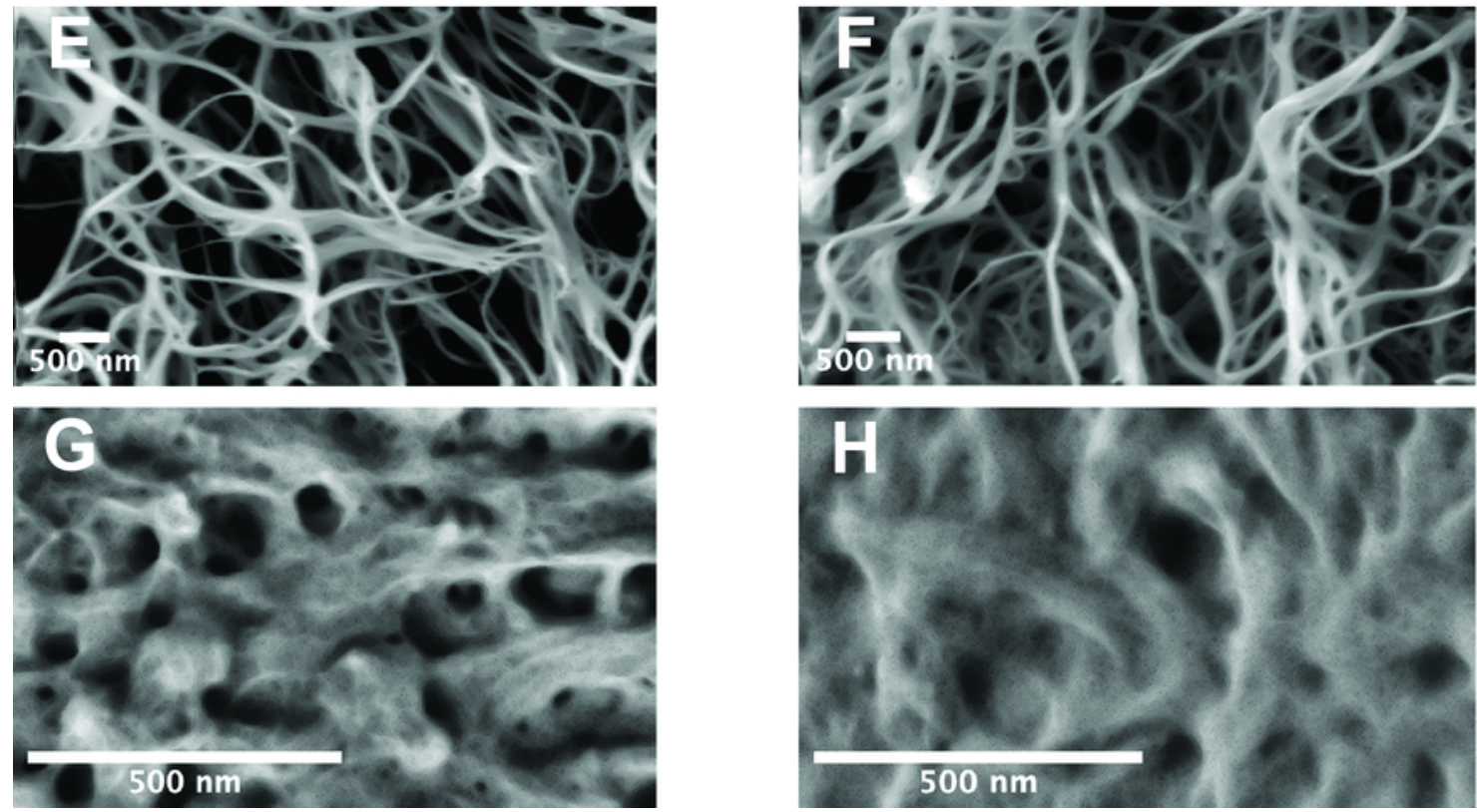

Figure 1

Hydrogels microstructure: Overall microstructure of fibrin hydrogels shown in (A) atomic force microscopy (AFM) and (E) scanning electron microscopy (SEM) was not affected after the inclusion of COAM (B) AFM and (F) SEM, while the microstructure of SAP hydrogels (homogeneity) (C) was affected 
after the inclusion of COAM leading to fiber aggregation (D) detected in AFM imaging, the effect of COAM inclusion on SAP hydrogels was not detected in SEM $(G)$ without $C O M$ and $(H)$ with COAM. Color code scale in AFM images (A, B, C \& D) represents fiber height. Scale bars in A, B, C \& D = $5 \mu \mathrm{m}$, and in E, F, G \& $\mathrm{H}=500 \mathrm{~nm}$.
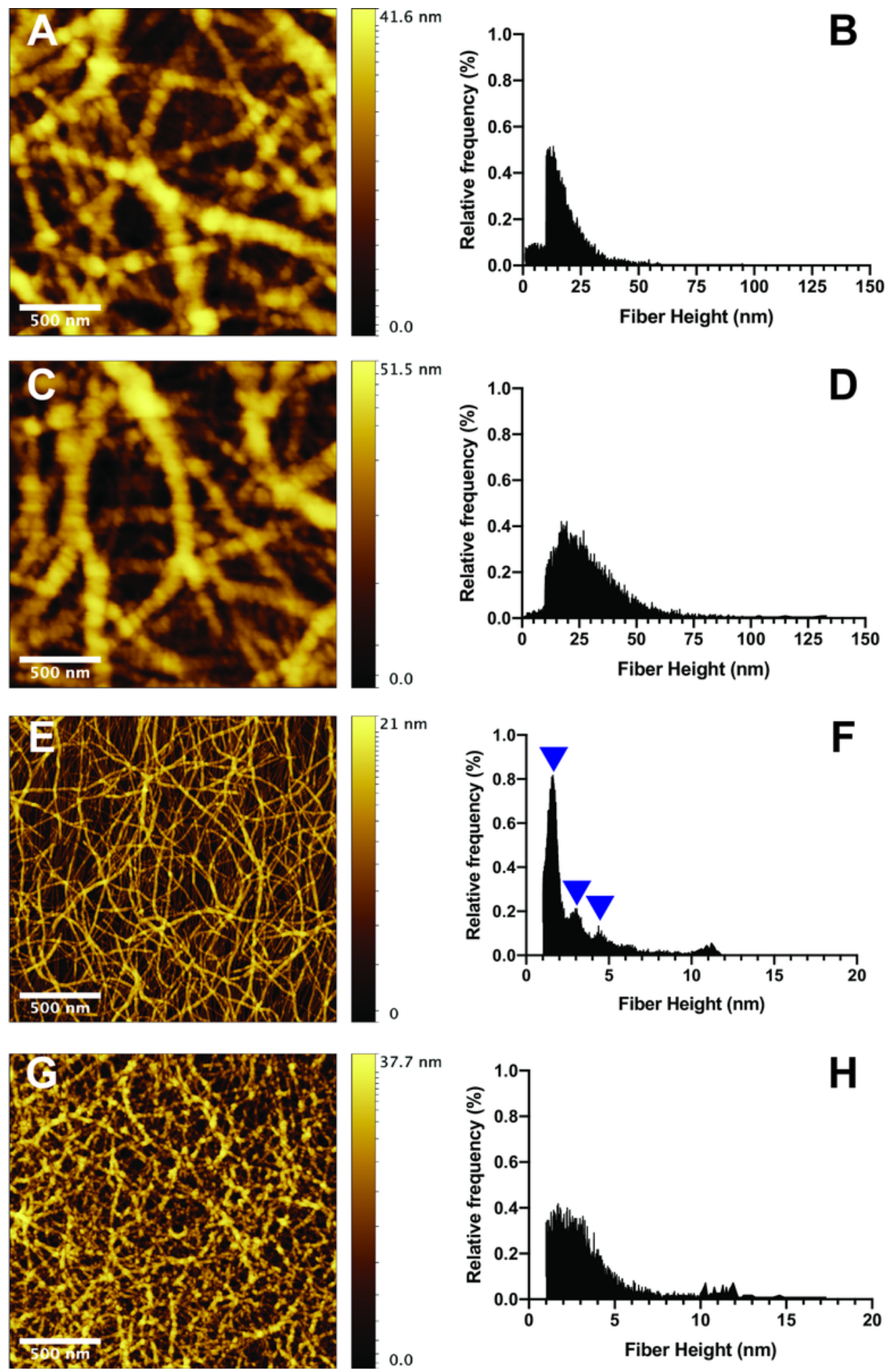

Figure 2 
High resolution atomic force microscopy (AFM) and quantitative fiber height distribution showed no significant effect for COAM inclusion on fibrin hydrogels (A \& B) without COAM and (C \& D) with COAM. SAP hydrogels without COAM (E) showed a distinct fiber height distribution with three peaks between 1 and $5 \mathrm{~nm}$ (blue arrow heads) $(F)$, after COAM inclusion $(G)$ these three peaks disappeared $(H)$ confirming aggregation at the fiber level.

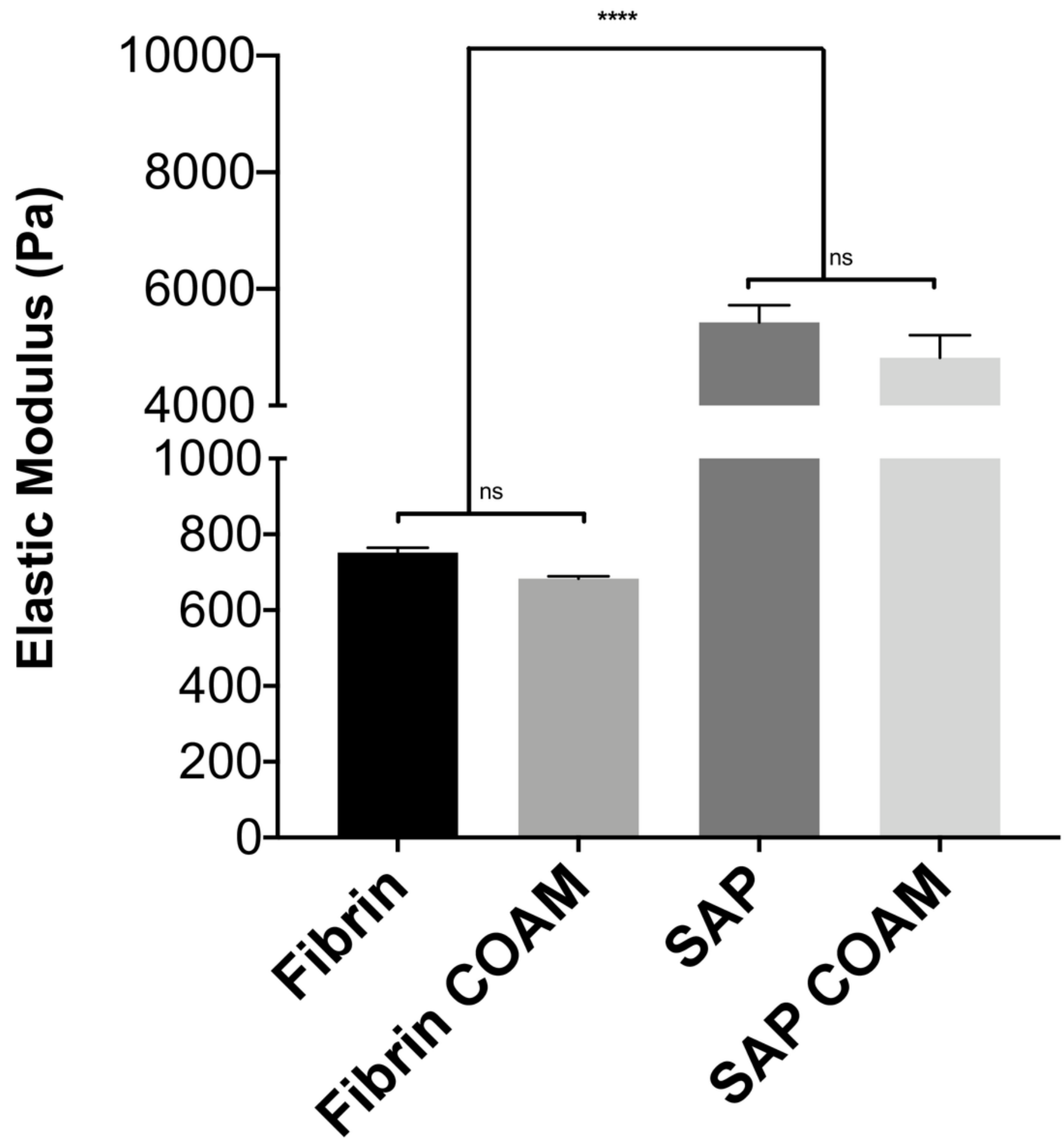

Figure 3 
Hydrogels stiffness: The elastic modulus for fibrin hydrogels at $3.5 \mathrm{mg} / \mathrm{ml}$ fibrinogen concentration and SAP hydrogels at $3.5 \mathrm{mg} / \mathrm{ml}$ RADA-16 concentration. Results are presented as mean $\triangle \mathrm{SEM}$; ns refers to not significant, * significant differences.

\section{Day 1}

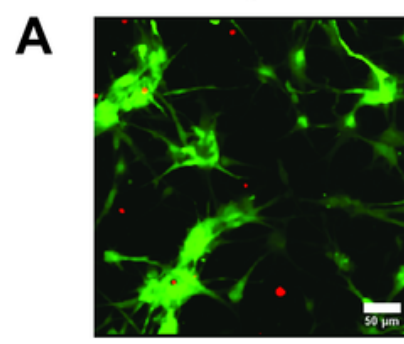

B

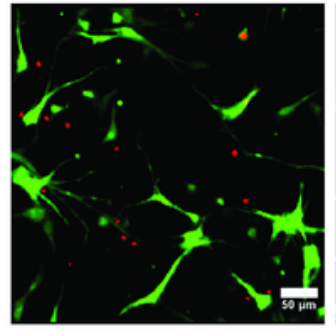

C

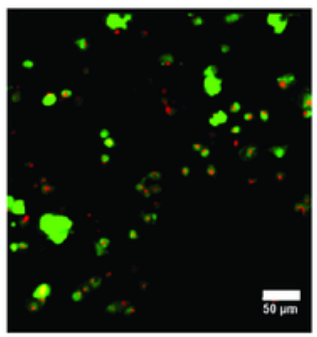

D
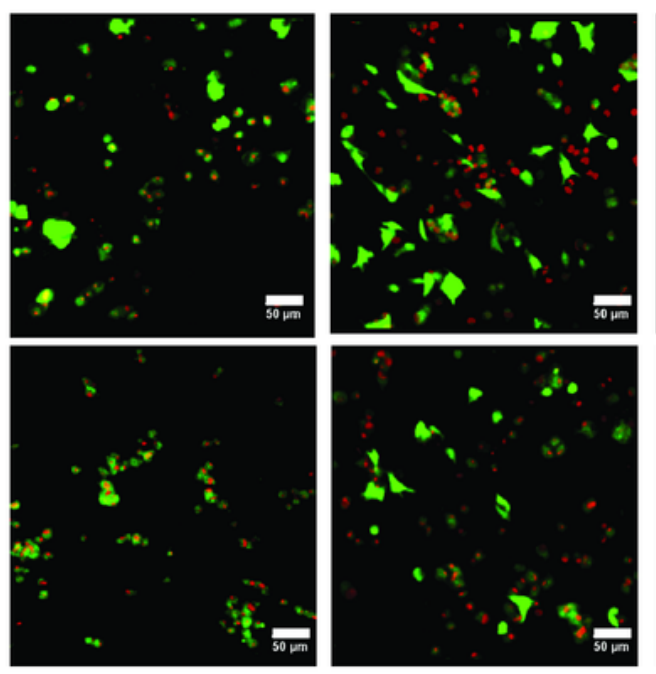

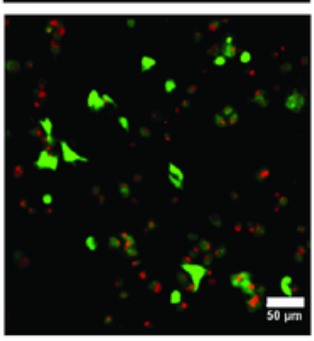

Day 4
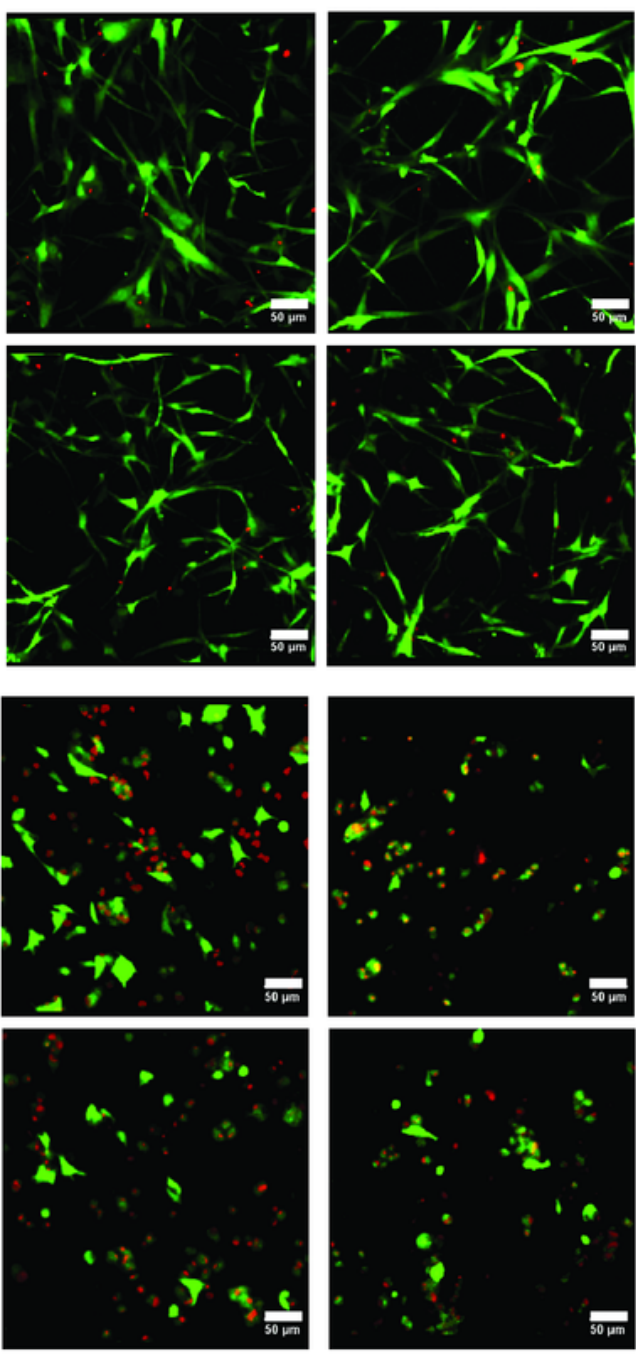

E

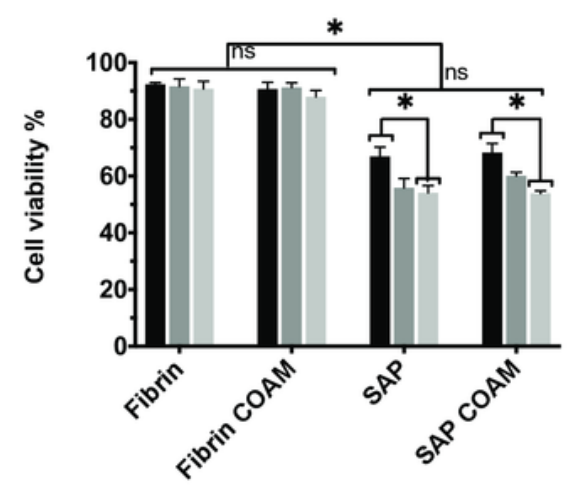

$\mathbf{F}$

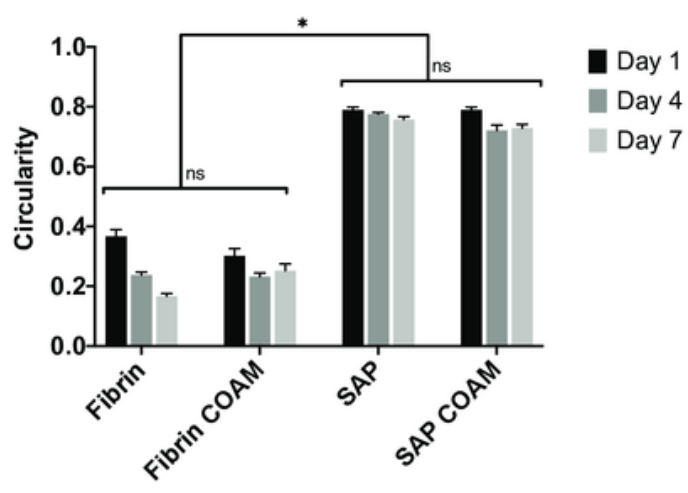

Figure 4

Cell viability (DPSCs) in cell-laden hydrogels cultured in maintenance medium was significantly higher in fibrin hydrogels (A) and with COAM (B) compared to SAP hydrogels (C) and with COAM (D) at each time 
point (E). For fibrin hydrogels $90.8 \%$ (D7), and with COAM $88.0 \%$ (D7) and for the SAP hydrogels $54.1 \%$ (D7), and with COAM 53.9\% (D7) (E). Further, DPSCs appeared to adopt a spread morphology in the fibrin hydrogels (A \& B), whereas they remained rounded in the SAP hydrogels (C \& D). (F) Cell shape (circularity) analysis confirmed the elongated morphology for DPSCs in fibrin hydrogels with and without COAM compared to the SAP hydrogels with and without COAM, indicating superior cellular attachment in fibrin hydrogels. Green is live cells and red is dead cells. Scale bars $=50 \mu \mathrm{m}$. Results are presented as mean $\triangle S E M$. ns refers to not significant, * significant differences.

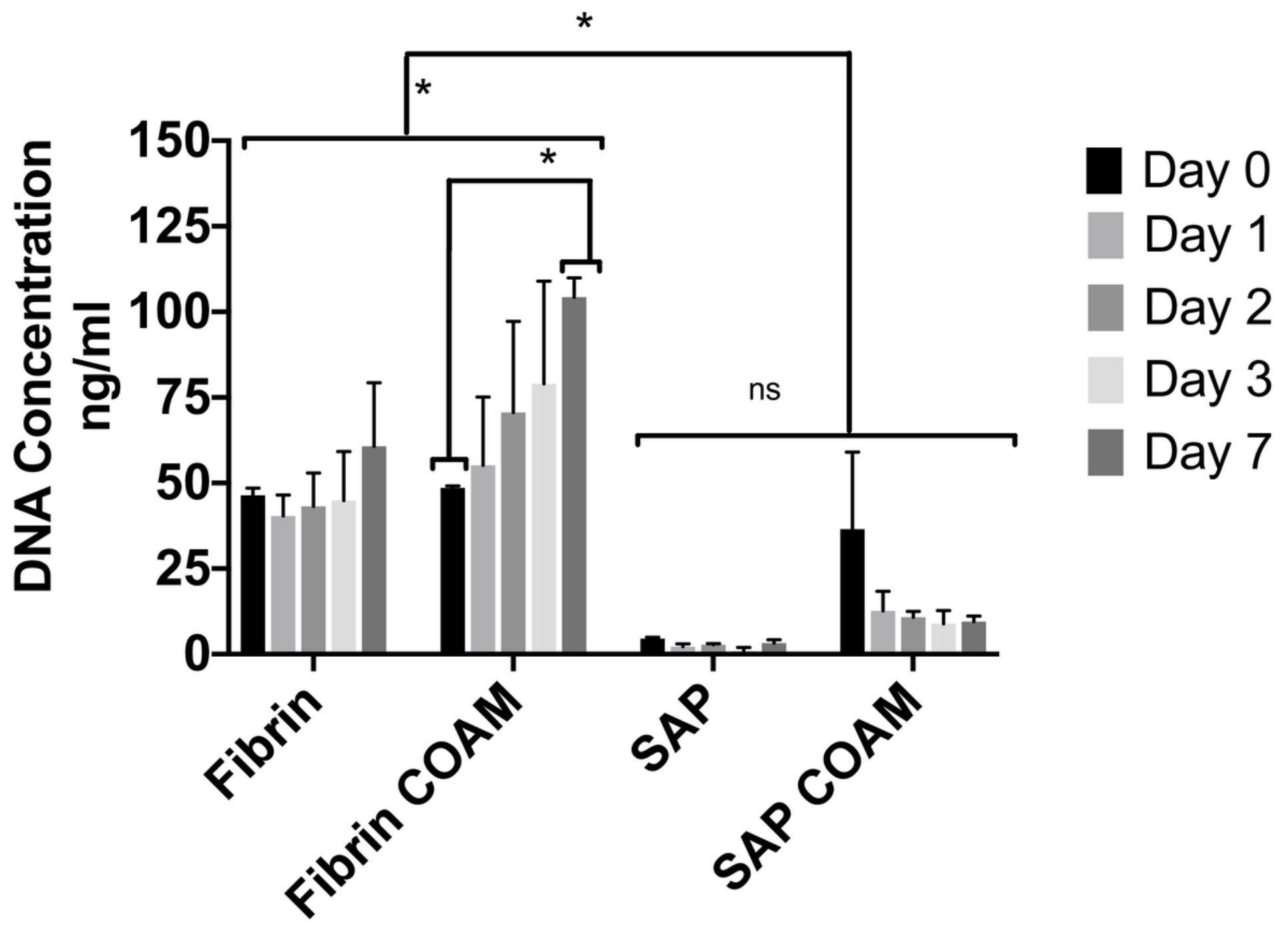

Figure 5

DNA content of cell-laden hydrogels cultured in serum free mesenchymal stem cells (MSCs) medium over a period of 7-days, showing significantly higher content and a proliferative pattern in fibrin hydrogels compared to SAP hydrogels. Results are presented as mean $\triangle \mathrm{SEM}$, ns refers to not significant, * significant differences. 